Review

\title{
Role of canonical Hedgehog signaling pathway in liver
}

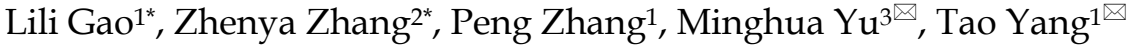 \\ 1. Center for Medical Research and Innovation, Shanghai Pudong Hospital, Fudan University Pudong Medical Center, Shanghai, 201399, China \\ 2. Department of general surgery, Hebei Medical University Fourth Hospital, Shijiazhuang, 050011, China \\ 3. Department of Oncology, Shanghai Pudong Hospital, Fudan University Pudong Medical Center, Shanghai 201399, China \\ *These two authors contributed equally to this work.
}

$\triangle$ Corresponding authors: Dr. Minghua Yu, Department of Oncology, Shanghai Pudong Hospital, Fudan University Pudong Medical Center, Shanghai 201399, China. Phone: 86-21-68030812; E-mail: ymh3011@163.com and Dr. Tao Yang, Center for Medical Research and Innovation, Shanghai Pudong Hospital, Fudan University Pudong Medical Center, 2800 Gongwei Road, Shanghai 201399, China. Phone: 86-21-68036516; E-mail: taoyang@tongji.edu.cn

(c) Ivyspring International Publisher. This is an open access article distributed under the terms of the Creative Commons Attribution (CC BY-NC) license (https://creativecommons.org/licenses/by-nc/4.0/). See http://ivyspring.com/terms for full terms and conditions.

Received: 2018.06.24; Accepted: 2018.08.01; Published: 2018.09.07

\begin{abstract}
Hedgehog $(\mathrm{Hh})$ signaling pathway plays an important role in embryonic development. It becomes reactivated in many types of acute and chronic liver injuries. Hh signaling is required for liver regeneration, regulates capillarisation, controls the fates of hepatic stellate cells, promotes liver fibrosis and liver cancers. In this review, we summarize the current knowledge of the role of canonical Hh signaling pathway in adult liver. This help to understand the pathogenesis of liver diseases and find out the new effective targeted therapeutic strategies for liver diseases treatments.
\end{abstract}

Key words: Hedgehog, liver, fibrosis, HCC

\section{Introduction}

Hedgehog $(\mathrm{Hh})$ signaling is a morphogenic signaling pathway that plays important roles in embryonic development. Hh signaling was first identified in Drosophila1. In 1980, Nusslein-Volhard et al. identified 15 loci that required for the establishment of segmental pattern in Drosophila, including Hedgehog ${ }^{1}$. In adult healthy liver, $\mathrm{Hh}$ signaling is considered to be inactive, because of mature hepatocytes barely express Hh ligands. Study shows that the basal level of Hh signaling pathway contributes to regulation of insulin-like growth factor I (IGF-I) hemostasis in healthy mature mouse hepatocytes ${ }^{2}$. Hh signaling becomes dramatically reactivated in various types of acute and chronic liver injuries (e.g., $70 \%$ partial hepatectomy $(\mathrm{PH})^{3}$, $\mathrm{HBV} / \mathrm{HCV}$ infection ${ }^{4}$, cholestatic liver injury ${ }^{5}$, ${ }^{6}$, alcoholic liver disease ${ }^{7}$ and non-alcoholic fatty liver disease $\left.(\mathrm{NAFLD})^{8}\right)$. Activation of $\mathrm{Hh}$ pathway promotes reconstruction of adult livers after injury. In this review, we summarize the role of canonical $\mathrm{Hh}$ signaling in liver regeneration, capillarisation, NAFLD, liver fibrosis and liver cancers.

\section{Hh signaling pathway in vertebrate}

In vertebrates, $\mathrm{Hh}$ signaling is initiated by $\mathrm{Hh}$ ligands (Sonic hedgehog (Shh), Indian hedgehog (Ihh) and Desert hedgehog (Dhh)). In addition to the key Hh signaling components, primary cilium is also required to properly transduce $\mathrm{Hh}$ signaling ${ }^{9,10}$. In the absence of Hh ligands, low levels of phosphatidylinositol 4-phosphate $(\mathrm{PI}(4) \mathrm{P})$ intact with Ptched (Ptch) receptor ${ }^{11}$. Ptch resides at the base of the primary cilium that represses Smoothened (Smo) receptor activity by preventing its accumulation within cilia ${ }^{12}$. Smo associates with small ubiquitinrelated modifier (SUMO)-specific isopeptidases, such as Ubiquitin-like protease 1 (Ulp1) in Drosophila and SUMO specific peptidases (SENP) family members in mammals, leading to its ubiquitination and degradation ${ }^{13}$. The downstream of Hh signaling pathway glioma-associated oncogene transcription factors (Glis, including Gli1, Gli2 and Gli3) associate with Suppressor of Fused (SuFu) and Kif7 to form the complex in the cytoplasm associated with microtubules. Protein kinase A (PKA) ${ }^{14}$, casein kinase Ia (Ckla) $)^{15}$ and glycogen synthase kinase $3 \beta$ $(G s k 3 \beta)^{16}$ promote phosphorylation of Glis to 

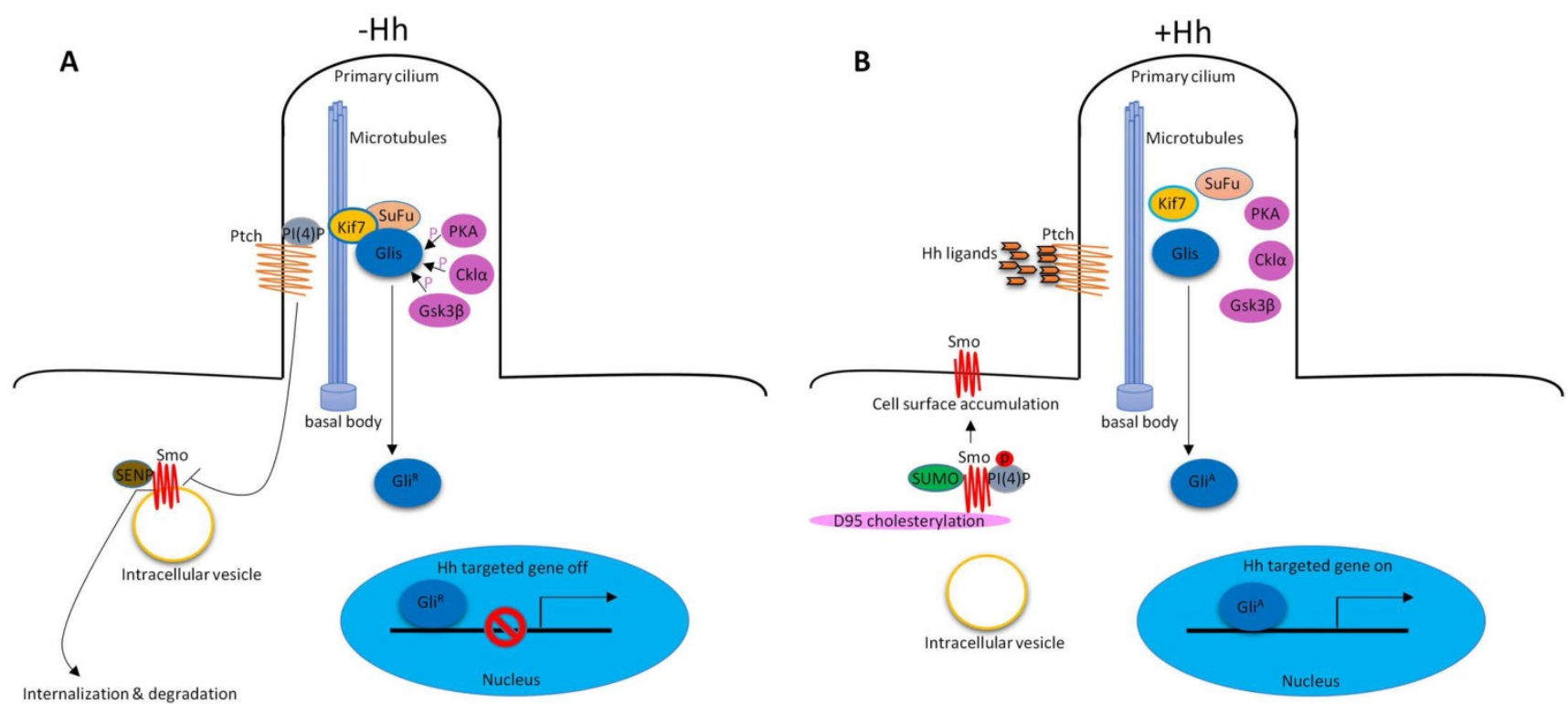

Figure 1. Hh signaling pathway in vertebrate. (A) In the absence of Hh ligands, low levels of PI(4)P intact with Ptch. Ptch represses Smo activity by preventing its accumulation within cilia. Smo associates with SENP family members leading to its ubiquitination and degradation. Glis associate with SuFu and Kif7 to form the complex in the cytoplasm associated with microtubules. PKA, Ckla and Gsk3ß promote phosphorylation of Glis to suppress their transcriptional activity (GliR). (B) In the presence of Hh ligands, inhibition of Smo by Ptch was relieved, leading to the translocation and accumulation of Smo at cilia. PI(4)P directly binds Smo which then triggers Smo phosphorylation. Sumoylation and cholesterol modification on D95 are also required for Hh signaling pathway activation. Glis dissociate the SuFu-Gli complex. Glis were in their active forms $(\mathrm{Gli})$. GliA enters into the nucleus to regulate gene expression.

suppress their transcriptional activity. Glis were in their repressor forms $\left(\mathrm{Gli}^{\mathrm{R}}\right)$. Hh signaling is inactive. (Figure 1A). In the presence of $\mathrm{Hh}$ ligands, the inhibition of Smo by Ptch was relieved, leading to the translocation and accumulation of Smo at cilia ${ }^{12}$. About the mechanisms of Smo movement and localization, study showed that diffusion was the predominant mode of motion of $\mathrm{Smo}^{17}$. Phosphorylation of Smo is required for Hh signaling pathway ${ }^{18}$. Hh stimulation elevates the production of PI(4)P. PI(4)P directly binds Smo through an arginine motif, which then triggers Smo phosphorylation and activation $^{11}$. Sumoylation ${ }^{13}$ and cholesterol modification $^{19}$ of Smo are also required for $\mathrm{Hh}$ signaling activation. After activation, Smo translocates to the tip of primary cilium and activates Glis by dissociating the SuFu-Gli complex. Glis were in their active forms $\left(\mathrm{Gli}^{\mathrm{A}}\right)$. $\mathrm{Gli}^{\mathrm{A}}$ enters into the nucleus to regulate gene expression (Figure 1B). There are also some molecules that are required for Hh signaling pathway activation, such as, pitchfork (Pifo), the G protein-coupled receptor associated sorting protein 2 (Gprasp2) and Growth Arrest Specific 8 (Gas8) are essential components of an $\mathrm{Hh}$ induced ciliary targeting complex able to regulate Smo translocation to the primary cilium ${ }^{20,21}$. Members of the four-member C-terminal EPS15-Homology Domain-containing (EHD) protein family EHD1 was shown to co-traffic with Smo by regulating the trafficking of Smo into the cilia in response to $\mathrm{Hh}$ activation $^{22}$.
Hh signaling pathway is well conserved between insects and vertebrates ${ }^{23}$. Ligands dependent, Smo mediated the activation of Glis (main components: $\mathrm{Hh}$ ligands, Ptch1 and Smo receptor, Glis transcription factors) are called canonical Hh signaling pathway. However, Glis activation may not require Smo. Glis can be activated by $\mathrm{Hh}$-independent mechanisms, such as, some cytokines (TNF- $\alpha$ and IL-1 $\beta$ ) activate Glis without activating $\mathrm{Smo}^{24}$. The downstream of Smo may not require Glis ${ }^{25}$, or mutations in components of the Hh signaling 26,27 can also activate Hh signaling pathway. These collectively called noncanonical Hh signaling pathway. The rest of this review will mainly discuss the diverse functions of canonical Hh signaling in adult liver.

\section{Hh signaling in liver regeneration}

Adult liver has enormous regenerative capacity which requires of proliferative activity in multiple types of liver cells, such as hepatocytes and progenitor cells. In acute massive loss of liver, e.g., $70 \%$ partial hepatectomy $(\mathrm{PH})$, people think liver regeneration relies largely upon increased replication of mature hepatocytes ${ }^{28}$. But the expression of progenitor markers, such as alpha-fetoprotein (AFP) and Fn14 increased, suggesting progenitor cells are also involved in liver regeneration post- $\mathrm{PH}^{29-31}$. In many types of chronic liver injury, since mature hepatocyte replication is inhibited, it is generally believed that progenitor populations mainly contribute to regeneration of chronically injured livers 28 . 
A

Adult healthy liver

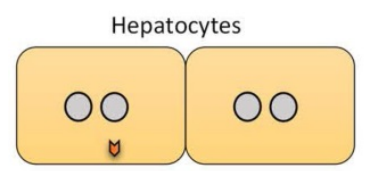

Hh ligands $\forall$
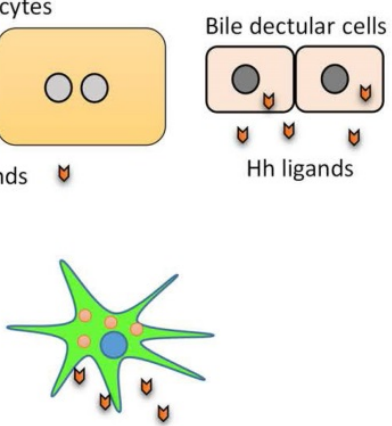

Hepatic stellate cells
B

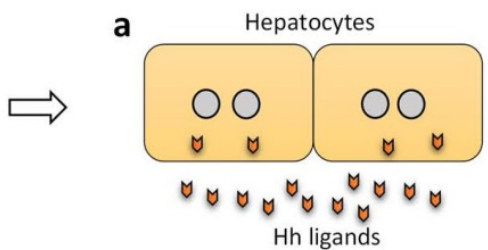

b

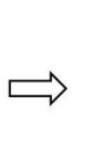

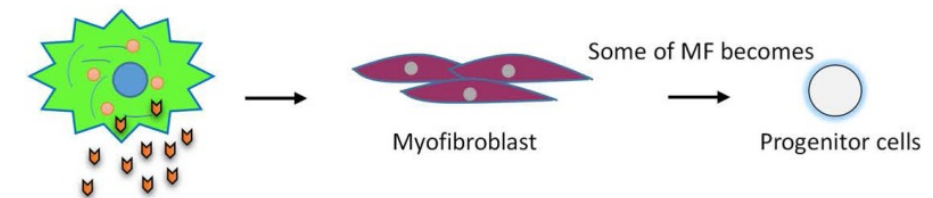

Activated hepatic stellate cells

C

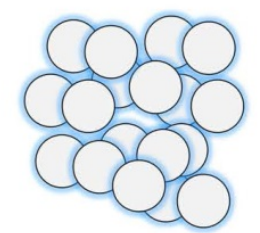

accumulation of progenitor cells

Figure 2. Hh signaling in required for liver regeneration post-PH. (A) In adult healthy liver, hepatocytes barely expressed Hh ligand. Bile ductular cells and hepatic stellate cells express $\mathrm{Hh}$ ligands, and have endogenous $\mathrm{Hh}$ pathway activity. (B) a) Hh pathway is activated in hepatocytes and bile ductular cells post-PH. b) $\mathrm{Hh}$ pathway is activated in hepatic stellate cells post-PH. Hh signaling promotes transition of quiescent hepatic stellate cells to myofibroblast. Some of myofibroblasts become progenitors that regenerate the liver epithelial compartment after $\mathrm{PH}$. c) Hh signaling promotes progenitor cell accumulation post-PH.

Hh signaling pathway is a major regulator of liver regeneration post $70 \% \mathrm{PH}$. After $\mathrm{PH}, \mathrm{Hh}$ signaling dramatically activated in hepatocyte, bile ductular cells and hepatic stellate cells (HSCs) ${ }^{3}$. Activation of $\mathrm{Hh}$ signaling activation promotes transition of quiescent HSC to fibrogenic myofibroblast (MF), some of MFs become progenitors that regenerate the liver epithelial compartment ${ }^{32}$. Thus Hh signaling activation promotes progenitor cell accumulation and fibrogenic liver repair after $\mathrm{PH}^{3,} 32$ (Figure 2). Hh signaling also regulates Hippo/Yes-associated protein 1 (Yap1) activation during liver regeneration after $\mathrm{PH}^{33}$. Yap1 is a morphogenic signaling pathway and Yap1 activation is also required for liver regeneration ${ }^{34}$. Study showed that Yap1 is a downstream effector of Hh signaling. In cultured HSC, disrupting Hh signaling blocked activation of Yap133.

\section{Hh signaling modulates capillarisation}

Liver sinusoidal endothelial cells (LSECs) have a unique phenotype which differs from all mammalian endothelial cells. LSECs have typical fenestrations clustered in sieve plates, lack an organized basement membrane and only have an attenuated extracelluar matrix consisting mostly of fibronectin ${ }^{35-37}$. LSECs lost this highly specialized morphology during a process called capillarisation ${ }^{36}$. Capillarisation occurs in many kinds of liver injuries and increases naturally with age ${ }^{35,38-40}$. Vascular remodeling during liver damage involves loss of healthy LSEC phenotype via capillarisation $^{36}$. Hh signaling is activated during LSEC capillarisation. Both in the mdr2-/- mice (a model of chronic liver injury and repair that results in progressive biliary-type fibrosis) and in the $70 \%$ partial hepatectomy model (a model of acute massive liver cell loss), inhibiting $\mathrm{Hh}$ signaling prevented capillarisation in both chronic and acute liver injury ${ }^{36}$.

\section{Hh signaling in NAFLD, NASH and liver fibrosis}

Non-alcoholic fatty liver disease (NAFLD) is now one of the most prevalent liver diseases in the world ${ }^{41}$. Hepatic steatosis is the hallmark feature of NAFLD and has the potential to develop into more severe steatohepatitis (NASH), which is characterized by fat accumulation, inflammation, and hepatocyte ballooning and can progress to liver fibrosis ${ }^{42,43}$. Liver fibrogenesis is a dynamic and highly integrated process that drives the progression of chronic liver diseases towards liver cirrhosis, hepatic failure and HCC 44,45 .

In NAFLD patients, Hh pathway activation is highly correlated with the severity of liver damage (e.g., portal inflammation, ballooning, and fibrosis stage) and with metabolic syndrome parameters that are known to be predictive of advanced liver disease ${ }^{8}$. In patients with NASH, ballooned hepatocytes underwent endoplasmic reticulum (ER) stress which induced the expression of $\mathrm{Shh}^{43}$. Ballooned hepatocytes produce and release Shh and provide a paracrine pro-fibrogenic signal to the neighboring 
cells ${ }^{43}$. Also, the autocrine Shh pathway in ballooned hepatocytes contributes to itself resistant to cell death due to the decreased caspase-946. Apoptosis can be divided into the extrinsic or death receptor pathway and the intrinsic or mitochondrial pathway ${ }^{47}$. The mitochondrial pathway was initiated by the activation of caspase-9. Loss of caspases function causes cells resist to apoptosis. Ballooned hepatocytes in NASH patients showed significantly decreased caspase-9 expression and resistant to apoptosis at least partly due to the Hh autocrine signaling pathway ${ }^{46}$.

The level of $\mathrm{Hh}$ pathway activity also significantly correlates with fibrosis stage ${ }^{48}$. HSCs are thought to be the key regulators of liver fibrosis, since active HSCs secrete fibrillar collagens, induce robust induction of a-smooth muscle actin (a-SMA), matrix molecules, matrix metalloproteinases (MMPs), and express tissue inhibitors of metalloproteinases (such as, TIMP-1 and TIMP-2), resulting in the accumulation of fibrotic extracellular matrix $(\mathrm{ECM})^{49-53}$. HSCs in adult livers express Shh and have endogenous $\mathrm{Hh}$ pathway activity ${ }^{54}$. During fibrogenesis, Hh signaling controls the fate of HSC, in vitro inhibiting Hh signaling in HSCs blocks HSCs activation ${ }^{54}$. Hh signaling promotes the transition of quiescent HSC (Q-HSC) to myofibroblastic hepatic stellate cells (MF-HSC), and provides an autocrine mechanism promoting the accumulation of MF-HSC. Many types of liver injuries trigger $\mathrm{MF}$ accumulation ${ }^{55,56}$. Some of MFs become progenitors that regenerate hepatocytes, cholangiocytes and $\mathrm{HSCs}^{32}$, 57. Hh signaling activation promotes accumulation of liver progenitors through activation
MFs. Overexpression of Shh in hepatocytes activated HSCs, upregulated various fibrogenic genes and led to liver fibrosis ${ }^{58}$. (Figure 3).

During fetal development, Hh pathway is a key regulator of angiogenesis and vasculogenesis ${ }^{59,} 60$. In adult liver, angiogenesis contributes to vascular remodeling during cirrhosis. Repair-related angiogenesis are regulated by ascular pericytes which promotes vascular tube formation. HSCs are liver-specific pericytes regulating angiogenesis during liver fibrosis ${ }^{61}$. Inhibiting $\mathrm{Hh}$ signliang with Cyclopamine (Smo inhibitor) or GANT-58 (Gli1 inhibitor) reduce the expression of vascular endothelial growth factor (VEGF) and angiopoietin 1 in HSCs and suppressed HSC tubulogenesis capacity $^{62}$.

Osteopontin (OPN) is an important component of the extracellular matrix (ECM). OPN levels have been highlighted as a potential biomarker of liver disease and correlates with the severity of liver fibrosis and inflammation ${ }^{63}$. OPN is Hh-regulated. Transcription factor Sex-determining region Y-box 9 (SOX9) lies downstream of Gli2. Hh signaling can modulate OPN through SOX964. In a mouse NAFLD model, activation of $\mathrm{Hh}$ signaling in hepatocytes increased the production of OPN, which subsequently enhanced the macrophage-mediated proinflammatory response through paracrine signaling 65 . (Figure 4A). Natural killer T cells (NKT cells) have endogenous Hh pathway activity ${ }^{66}$. Activated hepatic NKT cells secrete Hh ligands and associate OPN promotes HSC activation and promote liver fibrogenesis in a paracrine fashion ${ }^{67}$. (Figure 4B)

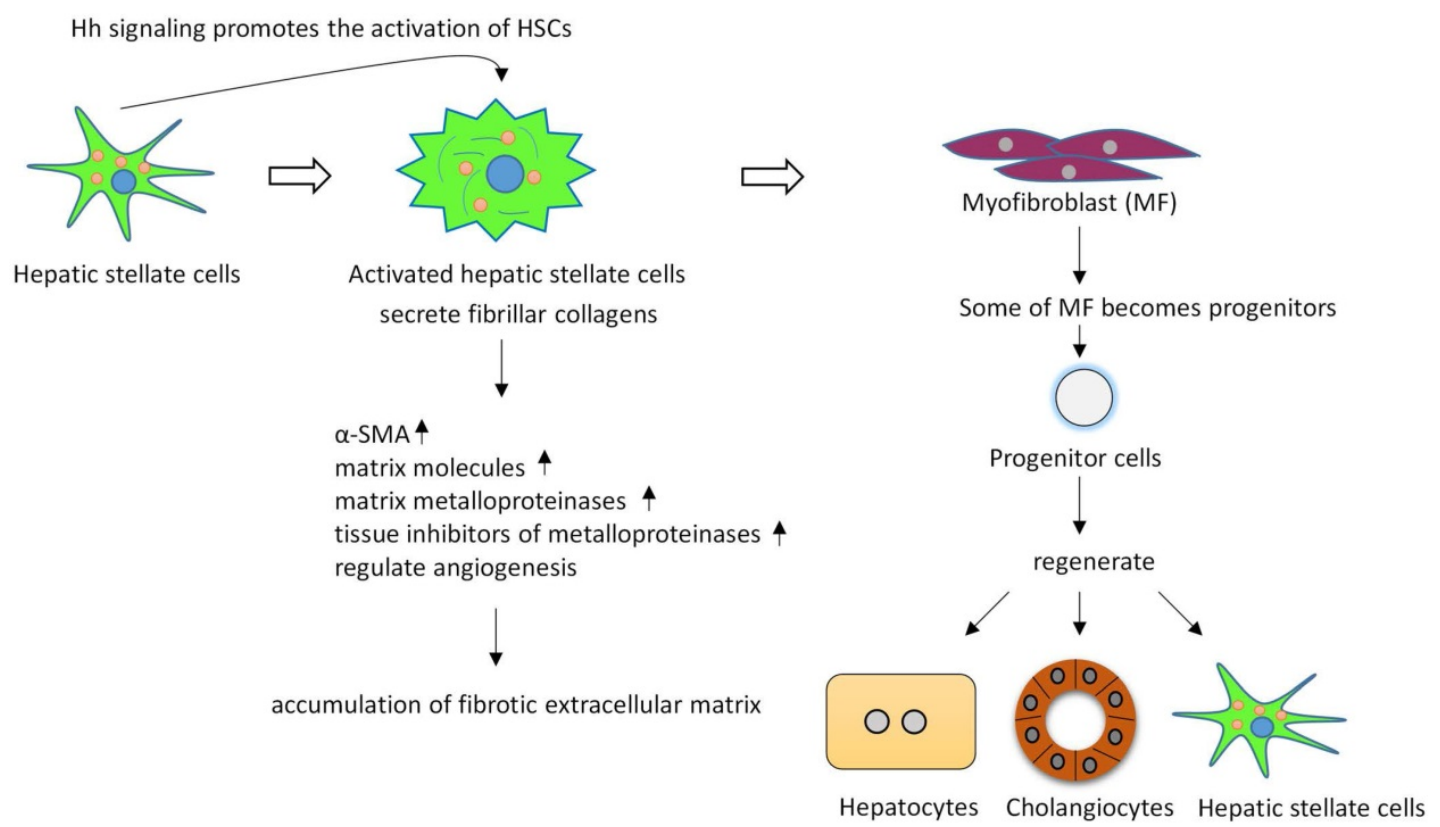

Figure 3. Hh signaling regulates the activation and viability of hepatic stellate cells and promotes liver fibrosis. Active hepatic stellate cells secrete fibrillar collagens, induce robust induction of a-SMA, matrix molecules, matrix metalloproteinases, and express tissue inhibitors of metalloproteinases, resulting in the accumulation of fibrotic extracellular matrix. Some of myofibroblasts can become multipotent progenitors to regenerate hepatocytes, cholangiocytes, and hepatic stellate cells. Blocking Hh signaling in myofibroblasts not only inhibited liver fibrosis but also prevented accumulation of liver progenitors. 
A

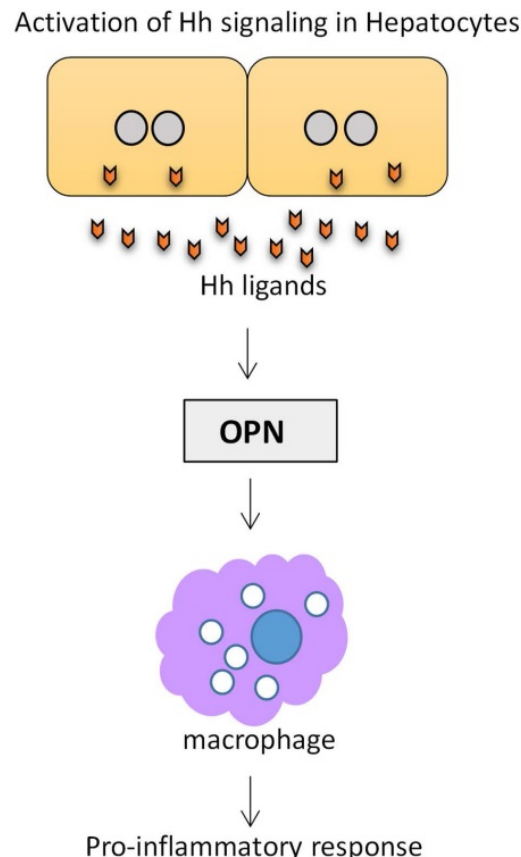

B

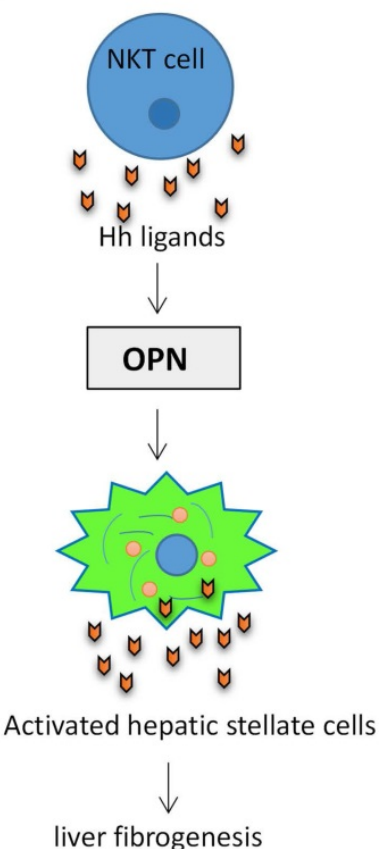

Figure 4. Activation of $\mathrm{Hh}$ signaling in hepatocytes and NKT cells promotes OPN production. (A) Activation of Hh signaling in hepatocytes increases the production of OPN, which subsequently enhanced the macrophage-mediated proinflammatory response. (B) Activation of Hh signaling in NKT cells associates OPN promotes HSC activation and liver fibrogenesis.

Hh signaling is a potential target for the treatment of NAFLD. The NIDDK-sponsored PIVENS trial (NCT00063622) showed that Vitamin E improved $\mathrm{NASH}^{68}$. Vitamin E treatment reduced Shh+ hepatocytes and improvement in Hh-regulated processes that promote NASH progression ${ }^{69}$. In a mouse NAFLD model, administration of Cyclopamine (Smo inhibitor) to high-fat diet-fed wild-type mice significantly reduced the numbers of activated macrophages and decreased the expression of proinflammatory cytokines ${ }^{65}$. Forskolin, a $\mathrm{Hh}$ signaling inhibitor significantly reduced CCl4-induced hepatic fibrosis ${ }^{70}$.

\section{Hh signaling in liver cancers}

\subsection{Hh signaling in hepatocellular carcinoma}

Hepatocellular carcinoma (HCC), the most common primary malignant tumor of the liver, is considered to be the third leading cause of all cancer-related deaths and fifth common cancer worldwide ${ }^{71,72}$. HCC is a complex and heterogeneous tumor with several genomic alterations. Aberrant activation of several signaling cascades (e.g., EGFR-Ras-MAPKK pathway, c-MET signaling, IGF signaling, PI3K/Akt/mTOR pathway, Wnt- $\beta$-catenin pathway, Hh signaling and apoptotic pathways) have been reported in $\mathrm{HCC}^{73}$.

The major cell populations that expanded during cirrhosis and HCC (MFs, activated endothelial cells, and progenitors) were Hh-responsive, higher levels of
Hh pathway activity associated with cirrhosis and $\mathrm{HCC}^{42}$. Hh signaling pathway components (Smo, Shh, Gli1 and Gli2) were higher in both HCC cell lines and tumor tissues from HCC patients ${ }^{74-76}$. Specific inhibition of Hh signaling in HCC cell lines by Smo antagonist, KAAD-cyclopamine, or with Shh neutralizing antibodies inhibits cell growth and results in apoptosis ${ }^{74}$. Hh inhibition induces autophagy through up-regulation of Bnip3 and that this mechanism contributes to apoptosis ${ }^{77}$. Among the Gli transcription factors, Gli2 plays a predominant role in the proliferation of HCC cells, targeting of Gli2 led to decreased proliferation of various HCC cell lines ${ }^{75}$

Hh signaling activation promotes hepatocarbinogenesis. Malignant hepatocytes produce Hh ligands. The paracrine soluble Hh ligands can stimulate glycolysis in neighboring MF resulting in release of MF-derived lactate that the malignant hepatocytes use as an energy source ${ }^{78}$. Overexpression of Shh in hepatocytes by hydrodynamic injection of Shh led to liver fibrosis, although it's not sufficient to induce liver tumors (persistent expression of Shh for up to 13 months in mice failed to induce tumors in the liver), it enhanced hepatocarcinogenesis induced by employing mouse hepatocellular adenoma (HCA) models induced by P53(R172H) and KRAS(G12D) ${ }^{58}$.

In some tumors Hh pathway is activated in a ligand-independent manner by inactivating mutations of Ptch179, 80. Ptch1, as a tumor suppressor 
that inhibits Smo, were reported that exhibits a higher expression in well and moderate differentiated HCC, but a lower expression in poorly differentiated $\mathrm{HCC}^{81}$. Three SNPs in Ptch1 (exon 12: T1665C and C1686T and exon 6: A1056G, no inactivating mutations of Ptch1 were found in this study) were identified in Chinese population. These SNPs showed no statistically significant for association with $\mathrm{HCC}^{81}$. The findings suggest that $\mathrm{Hh}$ pathway in Chinese HCC is activated by ligand expression but not by mutation $^{81}$. Overexpression of Smo, as well as an increase in the stoichiometric ratio of Smo to Ptch1 mRNA levels, correlated with tumor size ${ }^{82}$. Activation of the Smo mediates c-myc overexpression which plays a critical role in hepatocarcinogenesis ${ }^{82}$. MicroRNAs are involved in carcinogenesis. Loss of miR-338-3p expression is associated with clinical aggressiveness of HCC. It has been reported that Smo was a direct target of miR-338-3p. Inhibition of miR-338-3p induces HCC cells invasion by upregulating $\mathrm{Smo}^{76}$.

Surgery is the gold-standard treatment for local HCC and often complemented by radiofrequency ablation or transarterial chemoembolization. In advanced HCC, therapy options are limited and relapse and metastasis are common ${ }^{83}$. Sonidegib (LDE225), N-(6-((2S,6R)-2,6-dimethylmorpholino) pyridin-3-yl)-2-methyl-40-(trifluoromethoxy)biphenyl -3-carboxamide is a potent, selective and orally bioavailable inhibitor of the Hh signaling pathway. In the phase I trial, oral sonidegib was administered to 103 patients with advanced solid tumors, including medulloblastoma and basal cell carcinoma. Results showed that sonidegib has an acceptable safety profile and exhibits antitumor activity in advanced basal cell carcinoma and relapsed medulloblastoma, both of which are strongly associated with activated $\mathrm{Hh}$ pathway ${ }^{84}$. Sonidegib primarily metabolized by the liver. In order to make dose recommendations for patients with hepatic impairment, Horsmans et al. assessed the pharmacokinetics and safety of sonidegib in subjects with varying degrees of hepatic function. This phase I, multicenter, open-label study showed that sonidegib exposures were similar or decreased in the hepatic impairment groups compared with the normal group, and sonidegib was generally well-tolerated in all subjects. Dose adjustment is not considered necessary for subjects with mild, moderate, or severe hepatic impairment ${ }^{85}$. Sonidegib has already shown survival benefits in patients with advanced $\mathrm{HCC}^{73}$. Radiation-induced liver disease (RILD) is a major obstacle in treating HCC. Radiation-induced fibrosis constitutes a major problem that is commonly observed in the patients undergoing radiotherapy. Enhanced $\mathrm{Hh}$ signaling contributes to the RILD progression ${ }^{86}$. Male mice were exposed to single dose radiotherapy (6 Gy), both of Smo, Gli2 and Hh-target genes, were upregulated at 6 and 10 weeks after irradiation ${ }^{87}$. Correspondingly, when compared with radiotherapy alone, combining Cyclopamine (Shh inhibitor) with radiotherapy reduced the mean tumor size of orthotopic tumors ${ }^{88}$.

\subsection{Hh signaling in cholangiocarcinoma}

Cholangiocarcinoma (CCA) is the second most common primary liver tumor after $\mathrm{HCC}^{89}$. CCA and HCC display heterogeneity at both morphologic and molecular levels ${ }^{90}$. CCA represents a diverse group of epithelial cancers arising from varying locations with the biliary tree with very poor prognosis ${ }^{91}$. Based on their site of origin, CCA are classified into intrahepatic CCA (iCCA), perihilar CCA (pCCA), and distal CCA (dCCA $)^{92}$. Mature cholangiocytes basally express $\mathrm{Hh}$ ligands ${ }^{5}$. CCA cells produce and respond to Shh ligand ${ }^{93}$. A significant activation of the Hh signaling pathway was found in human $\mathrm{CCA}^{93-96}$. Ihh, Shh, Ptch1, Smo, Gli1, and Gli2 mRNA expressions were markedly increased in human ICC samples ${ }^{96}$. An autocrine Hh signaling in human CCA promotes CCA proliferation, migration, and invasion ${ }^{93}$.

Tumor necrosis factor-related apoptosisinducing ligand (TRAIL) induces apoptosis by binding its two cognate receptors death receptor 4 (DR4) and death receptor 5 (DR5) ${ }^{97}$. Many malignant cells remain resistant to TRAIL cytotoxicity. Using cholangiocarcinoma cells as a model for studying TRAIL resistance, Kurita et al. found that $\mathrm{Hh}$ signaling may contribute to TRIAL resistance in cancer cells ${ }^{95}$. Gli3 (but not Gli1 or Gli2) silences DR4 expression by binding to its promoter ${ }^{95}$. Blockade of Hh signaling sensitizes human CCA cell lines to TRAIL cytotoxicity by upregulating DR4 ${ }^{95}$. CCA is typically characterized by a dense desmoplastic stroma, of which cancer-associated myofibroblasts (MFBs) are a major cellular component ${ }^{98}$. These stromal MFBs have a crucial role in promoting CCA cells proliferation, migration and invasiveness through interactive autocrine and paracrine signaling pathway. Platelet-derived growth factor (PDGF)-BB as a MFB-derived survival factor for CCA cells promotes CCA resistance to TRAIL cytotoxicity in an Hh signaling-dependent manner by inducing cAMP/PKA-mediated Smo trafficking to the plasma membrane resulting in Gli2 nuclear translocation and Gli transcriptional activity ${ }^{99}$. Approximately $80 \%$ of human cancers (including CCA) express high levels of serine/threonine kinase polo-like kinase (PLK) transcripts in tumor cells and these PLK transcripts are mostly absent in surrounding healthy tissues ${ }^{100,101 .}$ Hh signaling may exert major survival signals in CCA 
by regulating PLK2. Hh signaling directly regulate PLK2 expression by binding of the Gli1 and Gli2 transcription factors to the PLK2 promoter ${ }^{102}$.

Survival of cholangiocarcinoma patients depends on the stage of disease at presentation, but even in patients with localised disease, five-year survival is poor at $15 \%$ and $30 \%$ for intrahepatic cholangiocarcinoma (ICC) and extrahepatic cholangiocarcinoma (ECC) respectively ${ }^{103}$. High Gli1 or Gli2 expressers had an unfavorable overall survival (OS) prognosis and a shorter disease-free survival $(\mathrm{DFS})^{96}$. Blocking $\mathrm{Hh}$ pathway inhibited EMT, decreased the viability of CCA cells and inhibited tumor growth in CCA xenografts ${ }^{93,}{ }^{94}$. Capsaicin, the most abundant pungent molecule produced by pepper plants, has been reported that interferes with the growth and proliferation and viability of human CCA cells through targeting the Hh pathway ${ }^{104}$. These findings suggest that inhibition of Hh pathway may be a possible treatment option for at least in a subset of human CCA in which the Hh pathway is activated.

\subsection{Hh signaling in hepatoblastoma}

Hh signaling pathway may play an important role in the differentiation and malignant potential of hepatoblastoma $(\mathrm{HB})$, the most common liver tumor in childhood, with most occurrences before the age of 3 years. Hh signaling pathway components (Shh, Ptch1, Smo and Gli1) were higher in patients with HB105-107. Smo or Gli1 expressions were positively correlated with tumor clinicopathological features, such as histological type, tumor grade, tumor size and clinical stage ${ }^{105}$. Inhibition of $\mathrm{Hh}$ signaling by Forskolin, a specific Hh signal inhibitor, suppressed the $\mathrm{HB}$ cell lines proliferation was associated with the down-regulation of C-Myc ${ }^{108}$.

\section{Summary}

Hh signaling is inactive in adult heathy liver, but it is activated during liver injuries of various etiologies. Hh signaling is required for liver regeneration, controls the fates of HSCs, modulates capillarisation and vasculogenesis, promotes liver fibrogenesis and liver cancers. Understanding the role of Hh signaling in liver helps us to develop new effective targeted strategies for the treatment of liver diseases.

\section{Acknowledgements}

The work was financially supported by National Natural Science Foundation of China (grant No. 81572518 \& 81372750) to T.Y., and International Technology Cooperation Project of Hebei Provincial Department of Science \& Technology (grant No: 13397708D) to Z.Y.Z.

\section{Competing Interests}

The authors have declared that no competing interest exists.

\section{References}

1. Nusslein-Volhard C, Wieschaus E. Mutations affecting segment number and polarity in Drosophila. Nature 1980;287:795-801.

2. Matz-Soja M, Aleithe S, Marbach E, Bottger J, Arnold K, Schmidt-Heck W, Kratzsch J, Gebhardt R. Hepatic Hedgehog signaling contributes to the regulation of IGF1 and IGFBP1 serum levels. Cell Commun Signal 2014;12:11.

3. Ochoa B, Syn WK, Delgado I, Karaca GF, Jung Y, Wang J, Zubiaga AM, Fresnedo O, Omenetti A, Zdanowicz M, Choi SS, Diehl AM. Hedgehog signaling is critical for normal liver regeneration after partial hepatectomy in mice. Hepatology 2010;51:1712-23.

4. Pereira Tde A, Witek RP, Syn WK, Choi SS, Bradrick S, Karaca GF, Agboola KM, Jung Y, Omenetti A, Moylan CA, Yang L, Fernandez-Zapico ME, Jhaveri R, Shah VH, Pereira FE, Diehl AM. Viral factors induce Hedgehog pathway activation in humans with viral hepatitis, cirrhosis, and hepatocellular carcinoma. Lab Invest 2010;90:1690-703.

5. Omenetti A, Yang L, Li YX, McCall SJ, Jung Y, Sicklick JK, Huang J, Choi S, Suzuki A, Diehl AM. Hedgehog-mediated mesenchymal-epithelial interactions modulate hepatic response to bile duct ligation. Lab Invest 2007;87:499-514

6. Omenetti A, Popov Y, Jung Y, Choi SS, Witek RP, Yang L, Brown KD, Schuppan D, Diehl AM. The hedgehog pathway regulates remodelling responses to biliary obstruction in rats. Gut 2008;57:1275-82

7. Jung Y, Brown KD, Witek RP, Omenetti A, Yang L, Vandongen M, Milton RJ, Hines IN, Rippe RA, Spahr L, Rubbia-Brandt L, Diehl AM. Accumulation of hedgehog-responsive progenitors parallels alcoholic liver disease severity in mice and humans. Gastroenterology 2008;134:1532-43.

8. Guy CD, Suzuki A, Zdanowicz M, Abdelmalek MF, Burchette J, Unalp A, Diehl AM, Nash CRN. Hedgehog pathway activation parallels histologic severity of injury and fibrosis in human nonalcoholic fatty liver disease. Hepatology 2012;55:1711-21.

9. Goetz SC, Ocbina PJ, Anderson KV. The primary cilium as a Hedgehog signal transduction machine. Methods Cell Biol 2009;94:199-222.

10. Wilson CW, Stainier DY. Vertebrate Hedgehog signaling: cilia rule. BMC Biol 2010;8:102.

11. Jiang K, Liu Y, Fan J, Zhang J, Li XA, Evers BM, Zhu H, Jia J. PI(4)P Promotes Phosphorylation and Conformational Change of Smoothened through Interaction with Its C-terminal Tail. PLoS Biol 2016;14:e1002375.

12. Rohatgi R, Milenkovic L, Scott MP. Patched1 regulates hedgehog signaling at the primary cilium. Science 2007;317:372-6.

13. Ma G, Li S, Han Y, Li S, Yue T, Wang B, Jiang J. Regulation of Smoothened Trafficking and Hedgehog Signaling by the SUMO Pathway. Dev Cell 2016;39:438-451.

14. Tukachinsky H, Lopez LV, Salic A. A mechanism for vertebrate Hedgehog signaling: recruitment to cilia and dissociation of SuFu-Gli protein complexes. J Cell Biol 2010;191:415-28.

15. Price MA, Kalderon D. Proteolysis of the Hedgehog signaling effector Cubitus interruptus requires phosphorylation by Glycogen Synthase Kinase 3 and Casein Kinase 1. Cell 2002;108:823-35.

16. Jia J, Amanai K, Wang G, Tang J, Wang B, Jiang J. Shaggy/GSK3 antagonizes Hedgehog signalling by regulating Cubitus interruptus. Nature 2002;416:548-52.

17. Milenkovic L, Weiss LE, Yoon J, Roth TL, Su YS, Sahl SJ, Scott MP, Moerner WE. Single-molecule imaging of Hedgehog pathway protein Smoothened in primary cilia reveals binding events regulated by Patched1. Proc Natl Acad Sci US A 2015;112:8320-5.

18. Chen $Y$, Jiang J. Decoding the phosphorylation code in Hedgehog signal transduction. Cell Res 2013;23:186-200.

19. Xiao X, Tang JJ, Peng C, Wang Y, Fu L, Qiu ZP, Xiong Y, Yang LF, Cui HW, He XL, Yin L, Qi W, Wong CC, Zhao Y, Li BL, Qiu WW, Song BL. Cholesterol Modification of Smoothened Is Required for Hedgehog Signaling. Mol Cell 2017;66:154-162 e10.

20. Jung B, Padula D, Burtscher I, Landerer C, Lutter D, Theis F, Messias AC, Geerlof A, Sattler M, Kremmer E, Boldt K, Ueffing M, Lickert H. Pitchfork and Gprasp2 Target Smoothened to the Primary Cilium for Hedgehog Pathway Activation. PLoS One 2016;11:e0149477.

21. Evron T, Philipp M, Lu J, Meloni AR, Burkhalter M, Chen W, Caron MG. Growth Arrest Specific 8 (Gas8) and G protein-coupled receptor kinase 2 (GRK2) cooperate in the control of Smoothened signaling. J Biol Chem 2011;286:27676-86.

22. Bhattacharyya S, Rainey MA, Arya P, Dutta S, George M, Storck MD, McComb RD, Muirhead D, Todd GL, Gould K, Datta K, Gelineau-van Waes J, Band V, Band H. Endocytic recycling protein EHD1 regulates primary cilia morphogenesis and SHH signaling during neural tube development. Sci Rep 2016;6:20727.

23. Huangfu D, Anderson KV. Signaling from Smo to Ci/Gli: conservation and divergence of Hedgehog pathways from Drosophila to vertebrates. Development 2006;133:3-14. 
24. Wang Y, Jin G, Li Q, Wang Z, Hu W, Li P, Li S, Wu H, Kong X, Gao J, Li Z. Hedgehog Signaling Non-Canonical Activated by Pro-Inflammatory Cytokines in Pancreatic Ductal Adenocarcinoma. J Cancer 2016;7:2067-2076.

25. Robbins DJ, Fei DL, Riobo NA. The Hedgehog signal transduction network. Sci Signal 2012;5:re6.

26. Johnson RL, Rothman AL, Xie J, Goodrich LV, Bare JW, Bonifas JM, Quinn AG, Myers RM, Cox DR, Epstein EH, Jr., Scott MP. Human homolog of patched, a candidate gene for the basal cell nevus syndrome. Science 1996;272:1668-71.

27. Xie J, Murone M, Luoh SM, Ryan A, Gu Q, Zhang C, Bonifas JM, Lam CW, Hynes M, Goddard A, Rosenthal A, Epstein EH, Jr., de Sauvage FJ. Activating Smoothened mutations in sporadic basal-cell carcinoma. Nature 1998;391:90-2.

28. Michalopoulos GK. Liver regeneration after partial hepatectomy: critical analysis of mechanistic dilemmas. Am J Pathol 2010;176:2-13.

29. Chiu JF, Gabryelak T, Commers P, Massari R. The elevation of alpha-fetoprotein messenger RNA in regenerating rat liver. Biochem Biophys Res Commun 1981;98:250-4.

30. Petropoulos C, Andrews G, Tamaoki T, Fausto N. alpha-Fetoprotein and albumin mRNA levels in liver regeneration and carcinogenesis. J Biol Chem 1983;258:4901-6

31. Bernuau D, Poliard A, Feldmann G. In situ cellular analysis of alpha-fetoprotein gene expression in regenerating rat liver after partial hepatectomy. Hepatology 1988;8:997-1005.

32. Swiderska-Syn M, Syn WK, Xie G, Kruger L, Machado MV, Karaca G, Michelotti GA, Choi SS, Premont RT, Diehl AM. Myofibroblastic cells function as progenitors to regenerate murine livers after partial hepatectomy. Gut 2014;63:1333-44

33. Swiderska-Syn M, Xie G, Michelotti GA, Jewell ML, Premont RT, Syn WK, Diehl AM. Hedgehog regulates yes-associated protein 1 in regenerating mouse liver. Hepatology 2016;64:232-44

34. Grijalva JL, Huizenga M, Mueller K, Rodriguez S, Brazzo J, Camargo F, Sadri-Vakili G, Vakili K. Dynamic alterations in Hippo signaling pathway and YAP activation during liver regeneration. Am J Physiol Gastrointest Liver Physiol 2014;307:G196-204

35. Xu B, Broome U, Uzunel M, Nava S, Ge X, Kumagai-Braesch M, Hultenby K, Christensson B, Ericzon BG, Holgersson J, Sumitran-Holgersson S. Capillarization of hepatic sinusoid by liver endothelial cell-reactive autoantibodies in patients with cirrhosis and chronic hepatitis. Am J Pathol 2003:163:1275-89.

36. Xie G, Choi SS, Syn WK, Michelotti GA, Swiderska M, Karaca G, Chan IS, Chen Y, Diehl AM. Hedgehog signalling regulates liver sinusoidal endothelial cell capillarisation. Gut 2013;62:299-309.

37. Wisse E, De Zanger RB, Charels K, Van Der Smissen P, McCuskey RS. The liver sieve: considerations concerning the structure and function of endothelial fenestrae, the sinusoidal wall and the space of Disse. Hepatology 1985;5:683-92.

38. DeLeve LD, Wang X, Kanel GC, Atkinson RD, McCuskey RS. Prevention of hepatic fibrosis in a murine model of metabolic syndrome with nonalcoholic steatohepatitis. Am J Pathol 2008;173:993-1001.

39. Warren A, Bertolino P, Benseler V, Fraser R, McCaughan GW, Le Couteur DG. Marked changes of the hepatic sinusoid in a transgenic mouse model of acute immune-mediated hepatitis. J Hepatol 2007;46:239-46.

40. Hilmer SN, Cogger VC, Fraser R, McLean AJ, Sullivan D, Le Couteur DG. Age-related changes in the hepatic sinusoidal endothelium impede lipoprotein transfer in the rat. Hepatology 2005;42:1349-54.

41. Farrell GC, Larter CZ. Nonalcoholic fatty liver disease: from steatosis to cirrhosis. Hepatology 2006;43:S99-S112.

42. Matz-Soja M, Rennert C, Schonefeld K, Aleithe S, Boettger J, Schmidt-Heck W, Weiss TS, Hovhannisyan A, Zellmer S, Kloting N, Schulz A, Kratzsch J, Guthke R, Gebhardt R. Hedgehog signaling is a potent regulator of liver lipid metabolism and reveals a GLI-code associated with steatosis. Elife 2016;5.

43. Rangwala F, Guy CD, Lu J, Suzuki A, Burchette JL, Abdelmalek MF, Chen W, Diehl AM. Increased production of sonic hedgehog by ballooned hepatocytes. J Pathol 2011;224:401-10.

44. Novo E, Cannito S, Paternostro C, Bocca C, Miglietta A, Parola M. Cellular and molecular mechanisms in liver fibrogenesis. Arch Biochem Biophys 2014:548:20-37.

45. Fattovich G, Stroffolini T, Zagni I, Donato F. Hepatocellular carcinoma in cirrhosis: incidence and risk factors. Gastroenterology 2004;127:S35-50.

46. Kakisaka K, Cazanave SC, Werneburg NW, Razumilava N, Mertens JC, Bronk $\mathrm{SF}$, Gores GJ. A hedgehog survival pathway in 'undead' lipotoxic hepatocytes. J Hepatol 2012;57:844-51.

47. Elmore S. Apoptosis: a review of programmed cell death. Toxicol Pathol 2007;35:495-516.

48. Syn WK, Jung Y, Omenetti A, Abdelmalek M, Guy CD, Yang L, Wang J, Witek RP, Fearing CM, Pereira TA, Teaberry V, Choi SS, Conde-Vancells J, Karaca GF, Diehl AM. Hedgehog-mediated epithelial-to-mesenchymal transition and fibrogenic repair in nonalcoholic fatty liver disease. Gastroenterology 2009;137:1478-1488 e8.

49. Bataller R, Brenner DA. Liver fibrosis. J Clin Invest 2005·115·209-18.

50. Hemmann S, Graf J, Roderfeld M, Roeb E. Expression of MMPs and TIMPs in liver fibrosis - a systematic review with special emphasis on anti-fibrotic strategies. J Hepatol 2007;46:955-75.

51. Friedman SL. Stellate cells: a moving target in hepatic fibrogenesis. Hepatology 2004;40:1041-3.
52. Han YP, Yan C, Zhou L, Oin L, Tsukamoto H. A matrix metalloproteinase-9 activation cascade by hepatic stellate cells in trans-differentiation in the three-dimensional extracellular matrix. J Biol Chem 2007;282:12928-39.

53. Arthur MJ, Stanley A, Iredale JP, Rafferty JA, Hembry RM, Friedman SL. Secretion of $72 \mathrm{kDa}$ type IV collagenase/gelatinase by cultured human lipocytes. Analysis of gene expression, protein synthesis and proteinase activity. Biochem J 1992;287 ( Pt 3):701-7.

54. Sicklick JK, Li YX, Choi SS, Qi Y, Chen W, Bustamante M, Huang J, Zdanowicz M, Camp T, Torbenson MS, Rojkind M, Diehl AM. Role for hedgehog signaling in hepatic stellate cell activation and viability. Lab Invest 2005;85:1368-80.

55. Nakatsukasa H, Evarts RP, Hsia CC, Thorgeirsson SS. Transforming growth factor-beta 1 and type I procollagen transcripts during regeneration and early fibrosis of rat liver. Lab Invest 1990;63:171-80.

56. Jakowlew SB, Mead JE, Danielpour D, Wu J, Roberts AB, Fausto N. Transforming growth factor-beta (TGF-beta) isoforms in rat liver regeneration: messenger RNA expression and activation of latent TGF-beta. Cell Regul 1991;2:535-48.

57. Xie G, Karaca G, Swiderska-Syn M, Michelotti GA, Kruger L, Chen Y, Premont RT, Choi SS, Diehl AM. Cross-talk between Notch and Hedgehog regulates hepatic stellate cell fate in mice. Hepatology 2013;58:1801-13.

58. Chung SI, Moon H, Ju HL, Cho KJ, Kim DY, Han KH, Eun JW, Nam SW, Ribback S, Dombrowski F, Calvisi DF, Ro SW. Hepatic expression of Sonic Hedgehog induces liver fibrosis and promotes hepatocarcinogenesis in a transgenic mouse model. J Hepatol 2016;64:618-27.

59. Dyer MA, Farrington SM, Mohn D, Munday JR, Baron MH. Indian hedgehog activates hematopoiesis and vasculogenesis and can respecify prospective neurectodermal cell fate in the mouse embryo. Development 2001;128:1717-30.

60. Vokes SA, Yatskievych TA, Heimark RL, McMahon J, McMahon AP, Antin PB, Krieg PA. Hedgehog signaling is essential for endothelial tube formation during vasculogenesis. Development 2004:131:4371-80.

61. Moreira RK. Hepatic stellate cells and liver fibrosis. Arch Pathol Lab Med 2007;131:1728-34.

62. Zhang F, Hao M, Jin H, Yao Z, Lian N, Wu L, Shao J, Chen A, Zheng S. Canonical hedgehog signalling regulates hepatic stellate cell-mediated angiogenesis in liver fibrosis. Br J Pharmacol 2017;174:409-423.

63. Huang W, Zhu G, Huang M, Lou G, Liu Y, Wang S. Plasma osteopontin concentration correlates with the severity of hepatic fibrosis and inflammation in HCV-infected subjects. Clin Chim Acta 2010;411:675-8.

64. Pritchett J, Harvey E, Athwal V, Berry A, Rowe C, Oakley F, Moles A, Mann DA, Bobola N, Sharrocks AD, Thomson BJ, Zaitoun AM, Irving WL, Guha IN, Hanley NA, Hanley KP. Osteopontin is a novel downstream target of SOX9 with diagnostic implications for progression of liver fibrosis in humans. Hepatology 2012;56:1108-16.

65. Kwon H, Song K, Han C, Chen W, Wang Y, Dash S, Lim K, Wu T. Inhibition of hedgehog signaling ameliorates hepatic inflammation in mice with nonalcoholic fatty liver disease. Hepatology 2016;63:1155-69.

66. Syn WK, Witek RP, Curbishley SM, Jung Y, Choi SS, Enrich B, Omenetti A, Agboola KM, Fearing CM, Tilg H, Adams DH, Diehl AM. Role for hedgehog pathway in regulating growth and function of invariant NKT cells. Eur J Immunol 2009;39:1879-92.

67. Syn WK, Agboola KM, Swiderska M, Michelotti GA, Liaskou E, Pang H, Xie G, Philips G, Chan IS, Karaca GF, Pereira Tde A, Chen Y, Mi Z, Kuo PC, Choi SS, Guy CD, Abdelmalek MF, Diehl AM. NKT-associated hedgehog and osteopontin drive fibrogenesis in non-alcoholic fatty liver disease. Gut 2012;61:1323-9.

68. Sanyal AJ, Chalasani N, Kowdley KV, McCullough A, Diehl AM, Bass NM, Neuschwander-Tetri BA, Lavine JE, Tonascia J, Unalp A, Van Natta M, Clark J, Brunt EM, Kleiner DE, Hoofnagle JH, Robuck PR. Pioglitazone, vitamin E, or placebo for nonalcoholic steatohepatitis. N Engl J Med 2010;362:1675-85.

69. Guy CD, Suzuki A, Abdelmalek MF, Burchette JL, Diehl AM, Nash CRN. Treatment response in the PIVENS trial is associated with decreased Hedgehog pathway activity. Hepatology 2015;61:98-107.

70. El-Agroudy NN, El-Naga RN, El-Razeq RA, El-Demerdash E. Forskolin, a hedgehog signalling inhibitor, attenuates carbon tetrachloride-induced liver fibrosis in rats. Br J Pharmacol 2016;173:3248-3260.

71. Bertuccio P, Turati F, Carioli G, Rodriguez T, La Vecchia C, Malvezzi M, Negri E. Global trends and predictions in hepatocellular carcinoma mortality. J Hepatol 2017;67:302-309.

72. Chacko S, Samanta S. "Hepatocellular carcinoma: A life-threatening disease". Biomed Pharmacother 2016;84:1679-1688.

73. Llovet JM, Bruix J. Molecular targeted therapies in hepatocellular carcinoma. Hepatology 2008;48:1312-27.

74. Huang S, He J, Zhang X, Bian Y, Yang L, Xie G, Zhang K, Tang W, Stelter AA, Wang $\mathrm{Q}$, Zhang $\mathrm{H}$, Xie J. Activation of the hedgehog pathway in human hepatocellular carcinomas. Carcinogenesis 2006;27:1334-40.

75. Kim Y, Yoon JW, Xiao X, Dean NM, Monia BP, Marcusson EG. Selective down-regulation of glioma-associated oncogene 2 inhibits the proliferation of hepatocellular carcinoma cells. Cancer Res 2007;67:3583-93.

76. Huang XH, Chen JS, Wang Q, Chen XL, Wen L, Chen LZ, Bi J, Zhang LJ, Su Q, Zeng WT. miR-338-3p suppresses invasion of liver cancer cell by targeting smoothened. J Pathol 2011;225:463-72.

77. Wang Y, Han C, Lu L, Magliato S, Wu T. Hedgehog signaling pathway regulates autophagy in human hepatocellular carcinoma cells. Hepatology 2013;58:995-1010. 
78. Chan IS, Guy CD, Chen $Y$, Lu J, Swiderska-Syn M, Michelotti GA, Karaca G, Xie G, Kruger L, Syn WK, Anderson BR, Pereira TA, Choi SS, Baldwin AS, Diehl AM. Paracrine Hedgehog signaling drives metabolic changes in hepatocellular carcinoma. Cancer Res 2012;72:6344-50.

79. Saito T, Mitomi H, Imamhasan A, Hayashi T, Kurisaki-Arakawa A, Mitani K, Takahashi M, Kajiyama Y, Yao T. PTCH1 mutation is a frequent event in oesophageal basaloid squamous cell carcinoma. Mutagenesis 2015;30:297-301.

80. Rodrigues AL, Carvalho A, Cabral R, Carneiro V, Gilardi P, Duarte CP, Puente-Prieto J, Santos P, Mota-Vieira L. Multiple nevoid basal cell carcinoma syndrome associated with congenital orbital teratoma, caused by a PTCH1 frameshift mutation. Genet Mol Res 2014;13:5654-63.

81. Fu X, Wang Q, Chen X, Huang X, Cao L, Tan H, Li W, Zhang L, Bi J, Su Q, Chen L. Expression patterns and polymorphisms of PTCH in Chinese hepatocellular carcinoma patients. Exp Mol Pathol 2008;84:195-9.

82. Sicklick JK, Li YX, Jayaraman A, Kannangai R, Qi Y, Vivekanandan P, Ludlow JW, Owzar K, Chen W, Torbenson MS, Diehl AM. Dysregulation of the Hedgehog pathway in human hepatocarcinogenesis. Carcinogenesis 2006;27:748-57.

83. Stotz M, Gerger A, Haybaeck J, Kiesslich T, Bullock MD, Pichler M. Molecular Targeted Therapies in Hepatocellular Carcinoma: Past, Present and Future. Anticancer Res 2015;35:5737-44.

84. Rodon J, Tawbi HA, Thomas AL, Stoller RG, Turtschi CP, Baselga J, Sarantopoulos J, Mahalingam D, Shou Y, Moles MA, Yang L, Granvil C, Hurh E, Rose KL, Amakye DD, Dummer R, Mita AC. A phase I, multicenter, open-label, first-in-human, dose-escalation study of the oral smoothened inhibitor Sonidegib (LDE225) in patients with advanced solid tumors. Clin Cancer Res 2014;20:1900-9.

85. Horsmans Y, Zhou J, Liudmila M, Golor G, Shibolet O, Quinlan M, Emotte C, Boss H, Castro H, Sellami D, Preston RA. Effects of Mild to Severe Hepatic Impairment on the Pharmacokinetics of Sonidegib: A Multicenter, Open-Label, Parallel-Group Study. Clin Pharmacokinet 2017.

86. Kim J, Wang S, Hyun J, Guy CD, Jung Y. Hedgehog Signaling is Associated with Liver Response to Fractionated Irradiation in Mice. Cell Physiol Biochem 2016;40:263-276.

87. Wang S, Lee Y, Kim J, Hyun J, Lee K, Kim Y, Jung Y. Potential role of Hedgehog pathway in liver response to radiation. PLoS One 2013;8:e74141.

88. Tsai CL, Hsu FM, Tzen KY, Liu WL, Cheng AL, Cheng JC. Sonic Hedgehog inhibition as a strategy to augment radiosensitivity of hepatocellular carcinoma. J Gastroenterol Hepatol 2015;30:1317-24.

89. Loosen SH, Vucur M, Trautwein C, Roderburg C, Luedde T. Circulating Biomarkers for Cholangiocarcinoma. Dig Dis 2018;36:281-288.

90. Zhang L, Bluth MH, Bhalla A. Molecular Diagnostics in the Neoplasms of the Pancreas, Liver, Gallbladder, and Extrahepatic Biliary Tract: 2018 Update. Clin Lab Med 2018;38:367-384

91. Razumilava N, Gores GJ. Cholangiocarcinoma. Lancet 2014;383:2168-79.

92. Razumilava N, Gores GJ. Classification, diagnosis, and management of cholangiocarcinoma. Clin Gastroenterol Hepatol 2013;11:13-21 e1; quiz e3-4.

93. El Khatib M, Kalnytska A, Palagani V, Kossatz U, Manns MP, Malek NP, Wilkens L, Plentz RR. Inhibition of hedgehog signaling attenuates carcinogenesis in vitro and increases necrosis of cholangiocellular carcinoma. Hepatology 2013;57:1035-45.

94. Riedlinger D, Bahra M, Boas-Knoop S, Lippert S, Bradtmoller M, Guse K, Seehofer D, Bova R, Sauer IM, Neuhaus P, Koch A, Kamphues C. Hedgehog pathway as a potential treatment target in human cholangiocarcinoma. J Hepatobiliary Pancreat Sci 2014;21:607-15.

95. Kurita S, Mott JL, Almada LL, Bronk SF, Werneburg NW, Sun SY, Roberts LR, Fernandez-Zapico ME, Gores GJ. GLI3-dependent repression of DR4 mediates hedgehog antagonism of TRAIL-induced apoptosis. Oncogene 2010;29:4848-58

96. Tang L, Tan YX, Jiang BG, Pan YF, Li SX, Yang GZ, Wang M, Wang Q, Zhang J, Zhou WP, Dong LW, Wang HY. The prognostic significance and therapeutic potential of hedgehog signaling in intrahepatic cholangiocellular carcinoma. Clin Cancer Res 2013;19:2014-24.

97. Johnstone RW, Frew AJ, Smyth MJ. The TRAIL apoptotic pathway in cancer onset, progression and therapy. Nat Rev Cancer 2008;8:782-98.

98. Sirica AE. The role of cancer-associated myofibroblasts in intrahepatic cholangiocarcinoma. Nat Rev Gastroenterol Hepatol 2011;9:44-54.

99. Fingas CD, Bronk SF, Werneburg NW, Mott JL, Guicciardi ME, Cazanave SC, Mertens JC, Sirica AE, Gores GJ. Myofibroblast-derived PDGF-BB promotes Hedgehog survival signaling in cholangiocarcinoma cells. Hepatology 2011;54:2076-88.

100. Schoffski P. Polo-like kinase (PLK) inhibitors in preclinical and early clinical development in oncology. Oncologist 2009;14:559-70.

101. Juntermanns B, Sydor S, Kaiser GM, Jaradat D, Mertens JC, Sotiropoulos GC, Swoboda S, Neuhaus JP, Meng W, Mathe Z, Baba HA, Canbay A, Paul A, Fingas CD. Polo-like kinase 3 is associated with improved overall survival in cholangiocarcinoma. Liver Int 2015;35:2448-57.

102. Fingas CD, Mertens JC, Razumilava N, Sydor S, Bronk SF, Christensen JD, Rizvi SH, Canbay A, Treckmann JW, Paul A, Sirica AE, Gores GJ. Polo-like kinase 2 is a mediator of hedgehog survival signaling in cholangiocarcinoma. Hepatology 2013;58:1362-74.

103. Kayhanian H, Smyth EC, Braconi C. Emerging molecular targets and therapy for cholangiocarcinoma. World J Gastrointest Oncol 2017;9:268-280.
104. Wutka A, Palagani V, Barat S, Chen X, El Khatib M, Gotze J, Belahmer $\mathrm{H}_{\text {, }}$ Zender S, Bozko P, Malek NP, Plentz RR. Capsaicin treatment attenuates cholangiocarcinoma carcinogenesis. PLoS One 2014;9:e95605.

105. Li YC, Deng YH, Guo ZH, Zhang MM, Zhu J, Pu CL, Xiang CP, Guo CB. Prognostic value of hedgehog signal component expressions in hepatoblastoma patients. Eur J Med Res 2010;15:468-74.

106. Oue T, Yoneda A, Uehara S, Yamanaka H, Fukuzawa M. Increased expression of the hedgehog signaling pathway in pediatric solid malignancies. J Pediatr Surg 2010;45:387-92.

107. Eichenmuller M, Gruner I, Hagl B, Haberle B, Muller-Hocker J, von Schweinitz D, Kappler R. Blocking the hedgehog pathway inhibits hepatoblastoma growth. Hepatology 2009;49:482-90.

108. Yamanaka H, Oue T, Uehara S, Fukuzawa M. Forskolin, a Hedgehog signal inhibitor, inhibits cell proliferation and induces apoptosis in pediatric tumor cell lines. Mol Med Rep 2010;3:133-9. 